\title{
PENGHITUNGAN KREDIBILITAS DENGAN PUSTAKA ACTUAR DALAM R
}

\author{
I. MAULIDI ${ }^{1}$, W. ERLIANA ${ }^{2}$,A.D. GARNADI ${ }^{2}$, S. NURDIATI ${ }^{2}$, I G. P. \\ PURNABA ${ }^{2}$
}

\begin{abstract}
Abstrak
Teori Kredibilitas (Credibility Theory) merupakan perangkat penting dalam pekerjaan aktuaria. Dengan menggunakan Kredibilitas dapat diduga besarnya pembayaran premi atau banyaknya klaim yang akan terjadi di masa mendatang secara kredibel. Dalam tulisan ini akan diperkenalkan konsep dalam teori kredibilitas dan aplikasinya dengan menggunakan paket Actuar yang ditulis menggunakan software $\mathrm{R}$.
\end{abstract}

\section{PENDAHULUAN}

Kredibilitas adalah sebuah ukuran penilaian seorang aktuaris terhadap dugaan premi di masa mendatang. Data di masa lampau tidak sepenuhnya dapat digunakan untuk menduga di masa mendatang, sehingga revisi dari penduga pun sering dilakukan. Selain itu risiko untuk setiap kelompok individu sangat dimungkinkan berbeda beda. Oleh karena itu kita perlu mengembangkan suatu analisis dari data di masa lampau untuk menduga data di masa mendatang. Sering kali data di masa lampau tidak stabil apabila digunakan untuk memprediksi premi di masa mendatang, sehingga revisi pendugaan sering kali dilakukan. Oleh karena itu diperlukan suatu tool untuk menggunakan data di masa lampau sehingga dapat memprediksi besarnya tingkat premi dan banyaknya klaim di masa mendatang.

Misalkan $X_{1}, X_{2}, \ldots, X_{n}$ merupakan besarnya kehilangan di $n$ tahun yang lalu atau $n$ pemegang polis yang lalu. Secara umum ini merupakan $n$ unit exposure yang diamati.

Asumsi

$$
\begin{gathered}
E\left[X_{j}\right]=\xi, \\
\operatorname{Var}\left(X_{j}\right)=\sigma^{2}, \\
\operatorname{Var}(\bar{X})=\frac{\sigma^{2}}{n},
\end{gathered}
$$

untuk $j=1, \ldots, n$ dan

\footnotetext{
1 Program Studi Matematika Universitas Syiah Kuala, Banda Aceh. Email: ikhsanmath47@gmail.com.

2 Departemen Matematika, Fakultas Ilmu Matematika dan Pengetahauan Alam, Jalan Meranti Kampus IPB, Dramaga Bogor, 16680.
} 


$$
\bar{X}=\frac{1}{n} \sum_{j=1}^{n} X_{j}
$$

Ada pun untuk menyatakan kredibilitas untuk $X$ kita harus mendefinisikan error relatif terlebih dahulu. Untuk suatu nilai peluang $p, p \in R, 0 \leq p \leq 1$ dan untuk tingkat error $\varepsilon$, jika dipenuhi

$$
P\left(\left|\frac{\bar{X}-\xi}{\xi}\right| \leq \varepsilon\right) \geq p,
$$

maka kita katakan $X$ adalah credible untuk $\xi$.

\section{BEBERAPA MODEL KREDIBILITAS}

\section{Model Buhlmann}

Model inimerupakan model kredibilitas yang paling sederhana. Padamasingmasingpemegang polis (bergantungpada $\Theta$ ), besarnyaklaimdari masa lalu $X_{1}, \ldots, X_{n}$ memilikirataandanragam yang samadani.i.dbergantungpada $\Theta$.

Didefinisikan

$$
\mu(\theta)=E\left(X_{j} \mid \Theta=\theta\right),
$$

dan

$$
v(\theta)=\operatorname{Var}\left(X_{j} \mid \Theta=\theta\right) .
$$

Dalamhalini $\mu(\theta)$ kitadisebutsebagaihypothetical meandan $v(\theta)$ disebutprocess variance.

Selanjutnyakitadapatmenentukanrataan, ragamdankoragam $X_{j}$ sebagaiberikut:

$$
\begin{aligned}
& E\left(X_{j}\right)=E\left[E\left(X_{j} \Theta\right)=E[\mu(\Theta)]=\mu,\right. \\
& \operatorname{Var}\left(X_{j}\right)=E\left[\operatorname{var}\left(X_{j} \Theta\right)+\operatorname{var}\left[E\left(X_{j} \Theta\right)\right]=\mu\right. \\
& =E(v(\Theta))+\operatorname{var}((\Theta)) \\
& =v+a, \\
& \operatorname{Cov}\left(X_{i} X_{j}\right)=E\left(X_{i} X_{j}\right)-E\left(X_{i}\right) E\left(X_{j}\right), i \neq j \\
& =E\left[E\left(X_{i} X_{j} \Theta\right)\right]-\mu^{2} \\
& =E\left(E\left(X_{i} \Theta\right) \cdot E\left(X_{j} \mid \Theta\right)\right)-[E(\mu(\Theta))]^{2} \\
& =E\left(((\Theta))^{2}\right)-[E(\mu(\Theta))]^{2} \\
& =\operatorname{Var}(\mu(\Theta))=a .
\end{aligned}
$$

Model pedugaanpremikredibilitasBuhlmanndihampiridengansuatufungsi linear berikut:

$$
\alpha_{o}+\sum_{j=1}^{n} \alpha_{j} X_{j}=Z \bar{X}+(1-Z) \mu
$$


dengan $Z=\frac{n}{k+n}, k=\frac{v}{a}=\frac{E\left[\operatorname{var}\left(X_{j} \mid \Theta\right)\right]}{\operatorname{var}\left[E\left(X_{j}\right) \mid \Theta\right]}$. Penurunan formula ini dapat dilihat pada Klugman (2012).

\section{Model Buhlmann Straub}

Model kredibilitasBuhlmann-Straub adalahpengembangandari model kredibilitasBuhlmanndenganbeberapaasumsitambahan. Diberikan $\Theta, X_{1}, \ldots, X_{n+1}$ saling bebas untuk $j=1,2, \ldots, n+1$, misalkan pula $m_{j}$ menyatakan banyaknya individu padatahunke-jmakaberlaku:

Selanjutnyakitanotasikansebagaiberikut:

$$
\begin{gathered}
E\left[X_{j} \mid \Theta\right]=\mu(\Theta), \\
\operatorname{Var}\left(X_{j} \mid \Theta\right)=\frac{v(\Theta)}{m_{j}} .
\end{gathered}
$$

$$
\begin{gathered}
\mu=E[\mu(\Theta)], a=\operatorname{Var}(\mu(\Theta)) \\
v=E[v(\Theta)], k=\frac{v}{a} .
\end{gathered}
$$

Kuantitas-kuantitas di atasdapatdigunakanuntukmenentukanpremikredibilitas. Premikredibilitasuntuk model Buhlmann-Straub iniadalah

$$
\begin{gathered}
(1-Z) \mu+Z \bar{X}, \\
\text { dengan } \bar{X}=\sum_{j=1}^{n} \frac{m_{j} X_{j}}{m}, Z=\frac{m}{m+k} \text {, dan } \sum_{j=1}^{n} m_{j}=m .
\end{gathered}
$$

\section{BEBERAPA CONTOH DAN APLIKASI}

\section{Contoh 1}

Misalkan banyaknya klaim tahunan untuk seorang individu yang diasuransikan memiliki sebaran Poisson. Nilai harapan frekuensi klaim tahunan (parameter Poisson $\Delta$ ) dari anggota populasi yang diasuransikan menyebar seragam $(0,1)$. Rataan frekuensi klaim tahunan individu adalah konstan sepanjang waktu. Tentukan faktor kedibilitas Buhlman $\mathrm{Z}$ jika ada $\mathrm{n}$ amatan.

Jawab:

Hypothetical meandapatditentukansebagaiberikut:

$$
\mu(\Delta)=E(X \mid \Delta)=\Delta,
$$

halinikarena

$X \mid \Delta$

menyebar

$\operatorname{Poisson}(\Delta)$.

Proses

variancedapatditentukansebagaiberikut: 


$$
V(\Delta)=\operatorname{var}(X \mid \Delta)=\Delta
$$

sehinggadiperolehkuantitas:

$$
\begin{aligned}
\mu=E(X) & =E(E(X \mid \Delta))=E(\mu(\Delta))=E(\Delta)=0.5 \\
v & =E(V(\Delta))=E(\Delta)=0.5 \\
\alpha & =\operatorname{var}(\mu(\Delta))=\operatorname{var}(\Delta)=\frac{1}{12}
\end{aligned}
$$

sehinggadiperolehfaktorkredibilitasBuhlmann

$$
Z=\frac{n}{n+\frac{1 / 2}{1 / 12}}=\frac{n}{n+6}
$$

\section{Contoh 2}

Misalkan $N_{j}$ menyatakan banyaknya klaim di tahun $j$, dimana terdapat $m_{j}$ anggota di tahun $j$ tersebut. Diberikan $\Theta=\theta, N_{j} \mid(\Theta=\theta) \sim \operatorname{Poisson}\left(m_{j} \theta\right)$ dan $\Theta \sim \operatorname{Gamma}(\alpha, \beta)$. Selanjutnya dari informasi tersebut kita dapat menentukan Buhlmann-Straub credibility premiumdari rata ratabanyaknyaklaimpadatahun $n+$ 1 untuk setiap anggota.

Jawab:

$$
\begin{aligned}
& \text { Misalkan } X_{j}=\frac{N_{j}}{m_{j}} \text {, maka } \\
& \begin{array}{c}
\mu(\Theta)=E\left[X_{j} \mid \Theta\right]=\frac{1}{m_{j}} E\left[N_{j} \mid \Theta\right]=\frac{1}{m_{j}} m_{j} \Theta=\Theta, \\
v(\Theta)=\operatorname{Var}\left(X_{j} \mid \Theta\right)=\frac{1}{m_{j}^{2}} \operatorname{Var}\left(N_{j} \mid \Theta\right)=\frac{1}{m_{j}^{2}} m_{j} \Theta=\frac{\Theta}{m_{j}}, \\
\mu=E[\mu(\Theta)]=E[\Theta]=\alpha \beta, \\
v=m_{j} E[v(\Theta)]=m_{j} \frac{1}{m_{j}} E[\Theta]=\alpha \beta, \\
a=\operatorname{Var}(\mu(\Theta))=\operatorname{Var}(\Theta)=\alpha \beta^{2}, \\
k=\frac{v}{a}=\frac{1}{\beta^{\prime}}
\end{array}
\end{aligned}
$$

sehinggadiperolehcredibility factor $Z=\frac{m}{m+k}=\frac{m \beta}{m \beta+1}$, dengan demikianBuhlmannStraub Credibilityuntuk model iniadalah

$$
\frac{m \beta}{m \beta+1} \bar{X}+\frac{1}{m \beta+1} \alpha \beta
$$




\section{PENGGUNAAN PACKAGES “ACTUAR" UNTUK KREDIBILITAS}

\section{Simulasi Data Hachemeister}

Berikut ini kami sajikan sebuah contoh simulasi menentukan besarnya premi dengan menggunakan model kredibilitas. Simulasi dilakukan dengan menggunakan software $\mathrm{R}$ dan packages "actuar" yang diperoleh dari CRAN. Data yang digunakan dalam simulasi adalah data dari Hachemesiter (1975) yang memuat besarnya klaim dan banyaknya klaim dari pemegang polis asuransi. Data ini terdapat dalam packages berupa matriks dengan banyaknya baris 5 dan banyaknya kolom adalah 25. Kolom 1 merepresentasikan kelompok dari pemegang polis, kolom 2-13 merepresentasikan rataan besarnya klaim setiap periode dan kolom 14-25 merepresentasikan banyaknya klaim setiap periode.

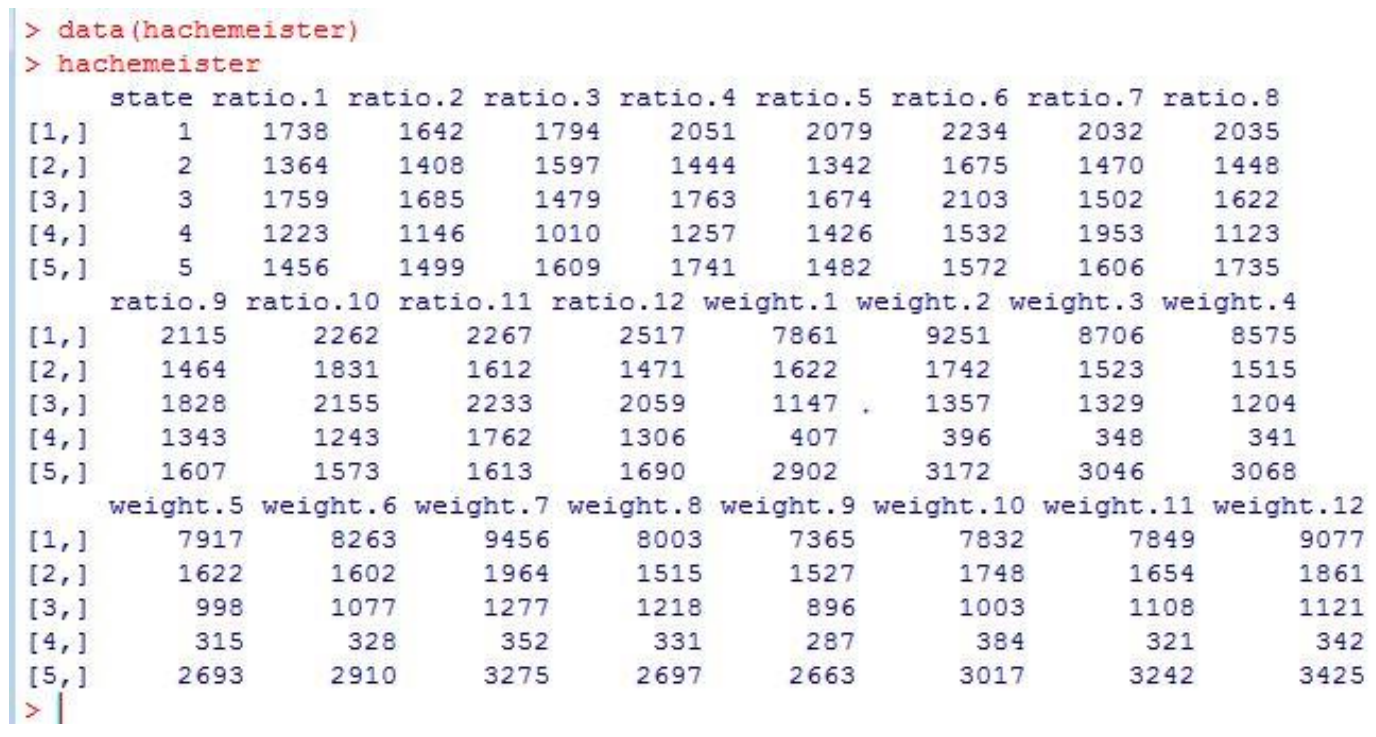

Fungsi yang digunakanuntuk model kredibilitasadalahfungsi $\mathrm{cm}$. Untuk model Buhlmanndimanatidakmempertimbangkanadanyapembobotan, premidapatditentukansebagaiberikut: 


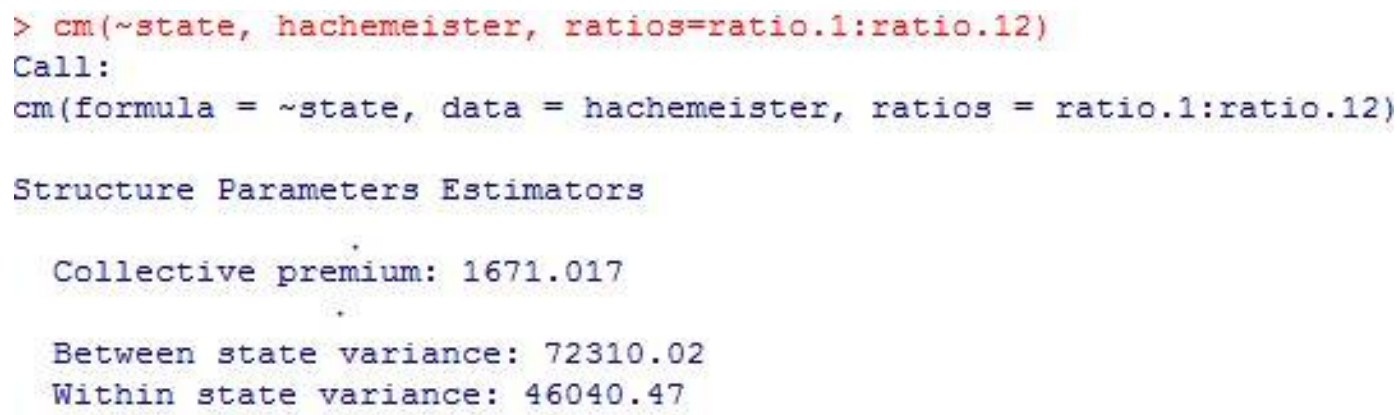

Berikuthasilsimulasiuntuk model Buhlmann-Straub (memperhitungkan adanyapembobotan) yang menggunakan model Bichsel Straub:

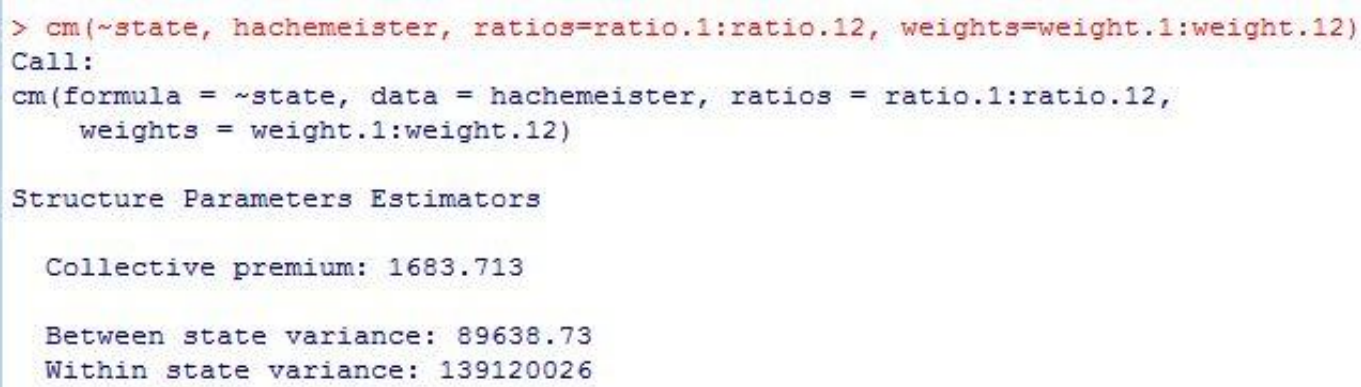

Dari simulasi di atasdiperolehnilaipremikredibilitasuntuk modelBuhlmannadalah 1671.017, sedangkanuntuk model Buhlmann-Straub diperolehpremikredibilitassebesar 1683.713.

\section{SimulasiContoh 1}

Untukmengujihasildaricontoh

1 , kami melakukansimulasidenganmembangkitkan data besarnyaklaim. Data tersebut kami sajikansebagaiberikut:

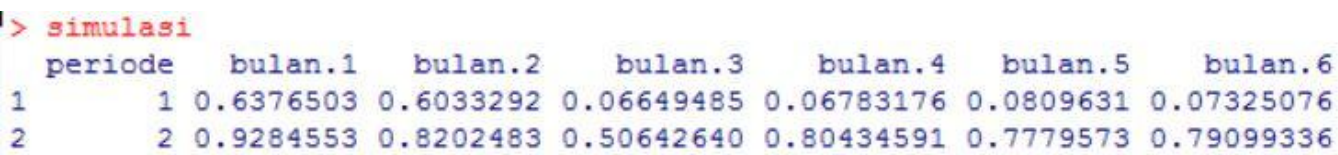

Dari data tersebutdiketahui $\bar{X}=0.513$. Dengan menggunakan formula Zdalamcontoh 1, diperoleh

$$
Z=\frac{n}{n+6}=\frac{12}{12+6}=0.67
$$

diperoleh hasil dugaan premi Buhlmann secarateorisebagaiberikut:

$$
(1-Z) \mu+Z \bar{X}=0.5088 \text {. }
$$


Denganmenggunakanperintah $\mathrm{cm}$ dalam package actuardiperolehhasil berikut:

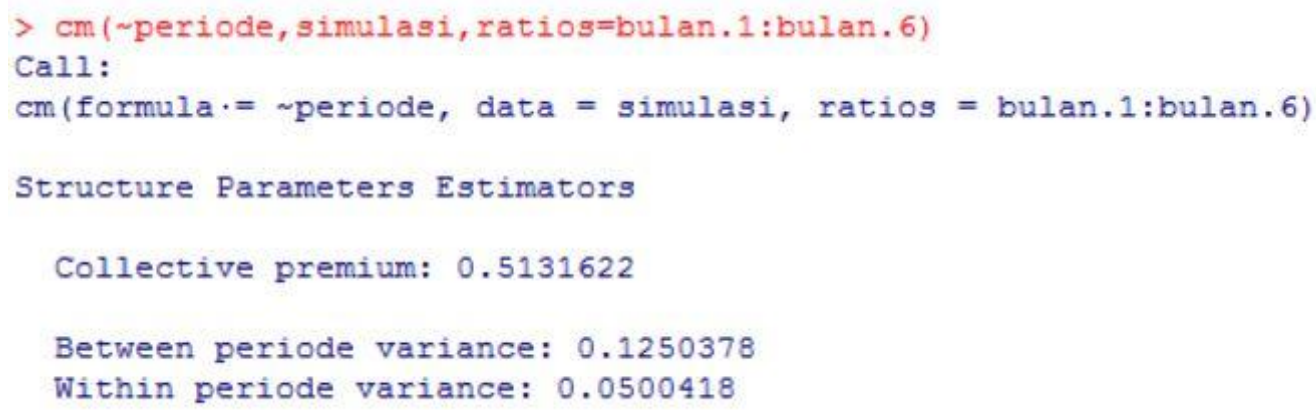

Terlihatbahwahasildugaanpremi yang diperolehadalah 0.5132 .

\section{UCAPAN TERIMA KASIH}

$\begin{array}{rlll}\text { Penelitianinididanaioleh } & \text { PUPT-IPB } & \text { under } & \text { contract } \\ \text { 079/SP2H/LT/DRPM/I I/2016. }\end{array}$

\section{DAFTAR PUSTAKA}

[1] Hachemeister CA. 1975. Credibility for regression models with application to trend. In credibility, theory and applications, Proceeding of the berkeley Actuarial Research Conference on Credibility, pages 129-163. New York: Academic Press.

[2] Buhlmann H,Gisler A. 2005.A course in credibility theory and its applications. Springer, ISBN 3-5402575-3-5.

[3] Buhlmann H, Straub E. 1970.Glaubgwurdigkeit fur Schadensatz. Bulletin of the Swiss Association of Actuaries, 70: 111-133.

[4] Klugman SA,et.al. 2012. Loss Models: From Data to Decisions. Wiley, ISBN 1118315324. 


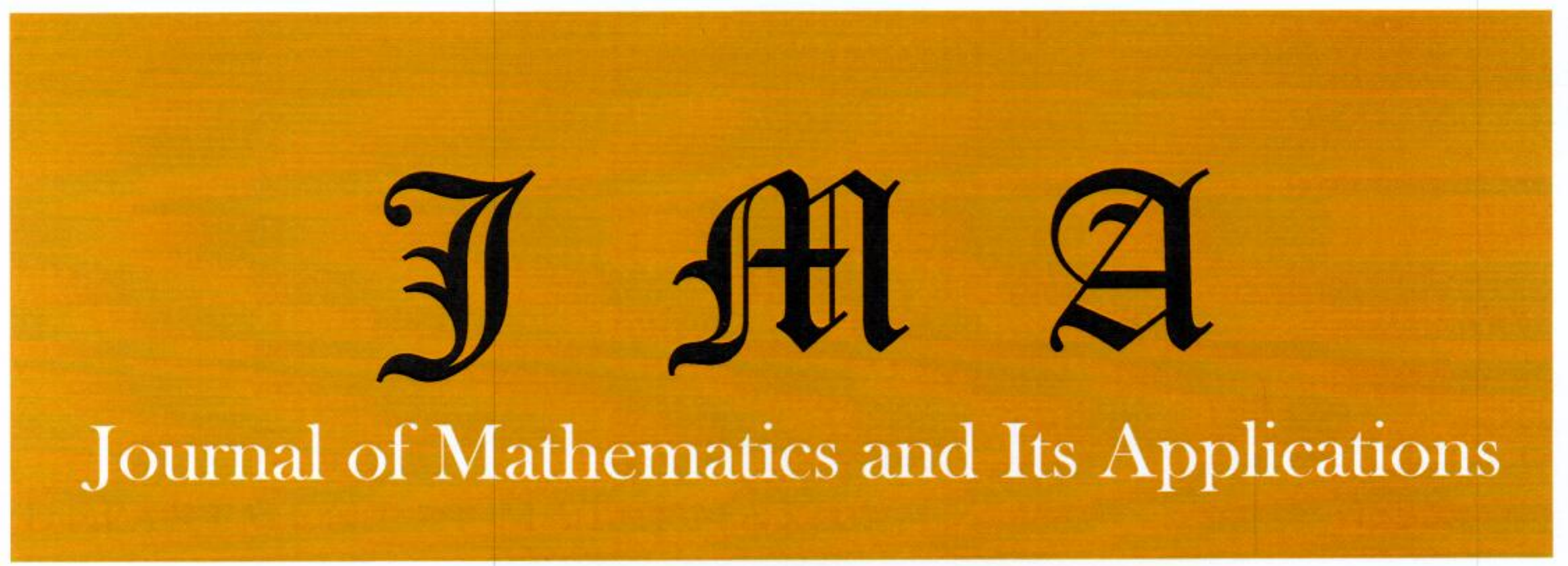

\section{Volume 16, No. 2}

\section{Desember 2017}

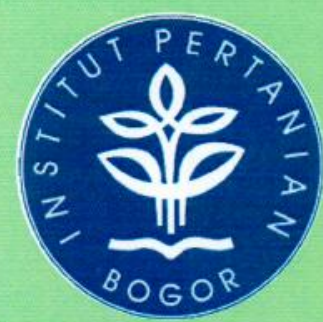

Department of Mathematics FMIPA - Institut Pertanian Bogor

JIn. Meranti, Kampus IPB Dramaga - Bogor

Phone/Fax: (0251) 8625276 E-mail: math@ipb.ac.id jma.mathipb@gmail.com
Kombinasi Varian Metode Newton dan Metode Halley untuk Menyelesaikan Persamaan Tak Linear D. A. Pratamasyari, B.P. Silalahi, dan S. Guritman

Penyusunan Algoritme Operasi Grup yang Dibangkitkan Oleh Kurva Hipereliptik $y^{2}+x y=x^{5}+x^{2}+x$ atas Lapangan $\mathrm{F}_{2}$ ?

S. Nurmalasari, S. Guritman, dan B. P. Silalahi

Model Matematika Penyebaran Penyakit Demam Berdarah Dengue Tipe SEIR Infeksi Ganda

E. N. Bano, P. Sianturi, dan Jaharuddin

Penghitungan Kredibilitas Dengan Pustaka Actuar Dalam $R$

I Maulidi, W. Erliana, A.D. Garnadi, S. Nurdiati, dan I G. P. Purnaba

Solusi Semi-Analitik Persamaan Laplace dengan Syarat Batas Campuran

I. Maulidi, A.D. Garnadi, M. N. Indro, M.T. Julianto, dan A. Pribadi

Penyelesaian Masalah Syarat Batas Persamaan Diferensial Biasa Menggunakan Metode Fungsi Green Secara Symbolic R. Kurnia, W. Erliana, A.D. Garnadi, S. Nurdiati, I G. P. Purnaba 


\title{
$\mathfrak{I} \mathfrak{A t A}$
}

Journal of Mathematics and Its Applications

\author{
Editor In Chief \\ I Wayan Mangku, Institut Pertanian Bogor
}

Executive Editor

Windiani Erliana, Institut Pertanian Bogor

Managing Editor

M. Tito Julianto, Institut Pertanian Bogor

Editorial Boards

Alhadi Bustamam Universitas Indonesia

Amril Aman

Institut Pertanian Bogor

Fahren Bukhari

Institut Pertanian Bogor

I Gusti Putu Purnaba

Institut Pertanian Bogor

Kiki Arianti Sugeng Universitas Indonesia

Paian Sianturi

Institut Pertanian Bogor

Saib Suwilo

Universitas Sumatera Utara

Siswadi

Subchan

Sugi Guritman

Institut Pertanian Bogor

Suhartono

Institut Teknologi Sepuluh Nopember

Tulus

Institut Pertanian Bogor

Institut Teknologi Sepuluh Nopember

Universitas Sumatera Utara

Department of Matematics

FMIPA - Institut Pertanian Bogor

Jalan Meranti, Kampus IPB Dramaga Bogor

Phone/Fax: (0251) 8625276

Email: math@ipb.ac.id,jma.mathipb@gmail.com

Website: www.math.ipb.ac.id/ojs

$\mathfrak{I} \mathfrak{A} \mathfrak{A}$ is published twice in a year, in July and December. Editor receives original research papers and critical survey articles in all area of mathematics. In preparing the manuscript, please follow the author guideline (attached on the back cover). 


\section{GUIDELINES FOR AUTHORS}

$\mathfrak{I} \mathfrak{A} \mathfrak{A} \mathfrak{A}$ is published twice in a year, in July and December and managed by Department of Mathematics, Institut Pertanian Bogor. Editor receives original research papers and critical survey articles in all area of mathematics. Article can be written in English or Indonesian. Article will be reviewed by editor using some criteria. Those are originality, significancy, technical strength, written presentation, and relevance to the journal. Author will be given for revising based on recommendation from reviewer/editorial boards. Manuscript could be submitted to:

\section{Department of Mathematics \\ FMIPA - Institut Pertanian Bogor \\ Jalan Meranti, Kampus IPB Dramaga Bogor \\ Phone/Fax: (0251) 8625276 \\ Email: math@ipb.ac.id, jma.mathipb@gmail.com}

Article is written using microsoft word, A4 paper, one column, Times New Roman font (14 size for title and 12 size for body text), single spacing. Upper/bottom/right margin is $3 \mathrm{~cm}$ and left margin is $4 \mathrm{~cm}$ (mirrored margin). No more than 20 pages.

Abstract is written in English or Indonesian, no more than 250 words. Keywords: 3-5 words.

Acknowledgment is written at the end of the paper before references.

References should be listed in alphabetical order according to the surnames of the authors at the end of the paper. The following reference style should be used:

[1] Brown RL. 1997. Introduction to the Mathematics of Demography. $3^{\text {rd }}$ Ed. Winsted: Actec Publications.

[2] Guritman S, Hooweg F, Simonis J. 2001. The Degree of Functions and Weights in Linear Codes. Discrete Applied Mathematics. 111(1): 87-102.

For specific details, please download $\mathfrak{I} A \mathfrak{A}\{$ template in the website www.math.ipb.ac.id/ojs. 


\section{$\mathfrak{I} \mathfrak{A} \mathfrak{A} \mathfrak{A}$}

Journal of Mathematics and Its Applications

Vol. 16, No. 2, December 2017

Kombinasi Varian Metode Newton dan Metode Halley untuk Menyelesaikan Persamaan Tak Linear

D. A. Pratamasyari, B.P. Silalahi, dan S. Guritman

Penyusunan Algoritme Operasi Grup yang Dibangkitkan Oleh Kurva Hipereliptik $y^{2}+x y=x^{5}+x^{2}+x$ atas Lapangan $\mathbb{F}_{2^{9 y}}$

S. Nurmalasari, S. Guritman, dan B. P. Silalahi

Model Matematika Penyebaran Penyakit Demam Berdarah Dengue Tipe SEIR Infeksi Ganda

E. N. Bano, P. Sianturi, dan Jaharuddin

Penghitungan Kredibilitas Dengan Pustaka Actuar Dalam $R$

I. Maulidi, W. Erliana, A.D. Garnadi, S. Nurdiati, dan I G. P. Purnaba

Solusi Semi-Analitik Persamaan Laplace dengan Syarat Batas Campuran

I. Maulidi, A.D. Garnadi, M. N. Indro, M.T. Julianto, dan A. Pribadi

Penyelesaian Masalah Syarat Batas Persamaan Diferensial Biasa Menggunakan Metode Fungsi Green Secara Symbolic

R. Kurnia, W. Erliana, A.D. Garnadi, S. Nurdiati, dan I G. P. Purnaba 